\title{
Effect of Mo, Ta, V and Zr on a duplex bcc+orthorhombic refractory complex concentrated alloy using diffusion couples
}

\author{
A. Lacour-Gogny-Goubert ${ }^{a, b}$, Z. Huvelin ${ }^{a, *}$, M. Perrut ${ }^{a}$, D. Boivin ${ }^{a}$, N. \\ Horezan $^{a}$, I. Guillot ${ }^{b}$, Ph. Vermaut ${ }^{c, d}$, J.P. Couzinie ${ }^{b}$ \\ ${ }^{a}$ DMAS, ONERA, Université Paris Saclay, 29, avenue de la Division Leclerc, 92320 \\ Châtillon, France. \\ ${ }^{b}$ Universite Paris-Est, Institut de Chimie et des Matériaux Paris-Est, UMR 7182 CNRS \\ - UPEC, 2, rue Henri Dunant, 94320 Thiais, France. \\ ${ }^{c}$ PSL Research University, Chimie ParisTech CNRS, Institut de Recherche de Chimie \\ Paris, 75005 Paris, France. \\ ${ }^{d}$ Sorbonne Universities, UPMC University Paris06, UFR 926, 75005 Paris, France.
}

\begin{abstract}
A scanning method based on diffusion couples has been set up to experimentally explore phase diagrams and to observe the stable phases in quinary alloys. This method enables to realize a fast, experimental and reliable scanning of composition and then determine promising alloy compositions for potential structural application. Aiming at developing promising refractory complex concentrated alloys (RCCAs), the method was applied on the Ti-Nb-Al-Si system with an initial two phase, body-centered cubic (bcc) + orthorhombic $(\mathrm{O})$, microstructure and focuses on the effect of Mo, Ta, V and $\mathrm{Zr}$ additions on this microstructure. The evolution of the orthorhombic phase fraction according to the content of additional elements was quantified, as well as the maximum concentration of those elements in order to stabilize the duplex microstructure, and maintain it above $800{ }^{\circ} \mathrm{C}$. In such framework, it appears that Mo, Ta and $\mathrm{V}$ show the most promising effects on the $\mathrm{Ti}-\mathrm{Nb}-\mathrm{Al}-\mathrm{Si}$ system. The comparisons between experimental results and calculated phase diagrams using current thermodynamic database showed that these calculations applied to RCCAs are good qualitative tools but are not accurate enough to be used as predictive means.
\end{abstract}

Keywords: Refractory Complex Concentrated Alloys, Alloy design, Diffusion couple, Microstructure, Intermetallics 


\section{Introduction}

The use of intermetallic alloys remains promising for high temperature applications in aircraft engines. The aerospace industry still requires low density alloys able to work in the range of $800{ }^{\circ} \mathrm{C}$ to $1000{ }^{\circ} \mathrm{C}$ while keeping high elevated temperature mechanical and environmental properties. To

5 meet such requirements, several trails were explored. The most recent concept has led to the development of high entropy alloys (HEAs) [1-3] and their derivative, so called complex concentrated alloys (CCAs) [4]. Especially, refractory complex concentrated alloys (RCCAs) are of interest since they display attractive mechanical properties at high temperature, but often show poor room temperature (RT) ductility and high density [5]. Most of these alloys have a single phase (bcc) microstructure [6] but could also contain other phases (bcc, hcp, B2, Laves phases...) [7, 8]. So far, one of the most promising microstructure has been obtained in $\mathrm{Al}_{0.5} \mathrm{NbTa}_{0.8} \mathrm{Ti}_{1.5} \mathrm{~V}_{0.2} \mathrm{Zr}$ with coherent ordered B2 precipitates in a disordered bcc matrix. However 15 its use is unfortunately limited under $600{ }^{\circ} \mathrm{C}$ [9]. This follows numerous attempts to obtain a $\gamma-\gamma^{\prime}$ like microstructure that until now led to a reverse B2+bcc microstructure [10].

Another approach is based on the formation of a bcc+orthorhombic microstructure in the $\mathrm{Ti}-\mathrm{Nb}-\mathrm{Al}$ system $[11,12]$. These alloys display the precipitation of a strengthening orthorhombic $(\mathrm{O})$ phase [13] providing high resistance at elevated temperature [14] while keeping reasonable room temperature (RT) ductility $[15,16]$. However, few data on the effect of other alloying elements to this ternary system were reported in literature and mostly limited to small amount of alloying element, around 2-3 at.\%. Among the different additional elements some are classified as $\beta$ stabilizers (Mo, $\mathrm{Si}, \mathrm{V}$, Ta, W): Mo $[17,18]$ enhances tensile strength and creep resistance, Si [17] improves creep and oxidation properties, V [18] decreases density and improves RT ductility, elevated temperature strength and creep resistance, Ta [19] increases yield strength and the $\mathrm{B} 2 / \beta$ transus, at the cost of higher density and $W[18]$ enhances high temperature resistance and creep resistance at the cost of higher density as well. Other elements such as Zr are considered as neutral $[17,20]$ and improve creep resistance.

The development of concentrated multicomponent $\mathrm{Ti}-\mathrm{Nb}-\mathrm{Al}$-based alloys faces the ongoing challenge of the phase prediction in such systems. Some 
methods of alloying design were already tested especially in the current HEA development. The most common approach is the CALPHAD (CALculation of PHAse Diagram) modeling, and previous attempts on HEAs [21-23] clearly demonstrated that the results depend on the quality of the thermodynamic database, and that complete binary and ternary thermodynamic data are needed for an accurate description of an alloy system. It also highlighted that CALPHAD modeling can give reliable predictions of the number and nature of stable phases but fails to accurately determine both phase transition temperature [24, 25], phase compositions and phase fractions [26]. Some other approaches have also been reported. Among those, one is based on the RHEAs [28], it was successfully carried out to trigger transformation induced plasticity (TRIP) effect in Ti-rich HEA. However, this approach is limited to potential RT applications.

In the $\mathrm{Ti}-\mathrm{Al}-\mathrm{Nb}$ system, none of the previous methods allow to deterprecisely the conter crostructure with a high volume fraction of the $\mathrm{O}$ phase. Therefore, another approach was chosen in this study, inspired by previous studies that used diffusion couples/multiples to map phase diagrams [29, 30]. In this approach, graded samples underwent long term aging in order to observe thermodynamically stable phases and to experimentally and reliably investigate phase diagrams [31]. The study of graded samples showing an evolution from a two-phase to a single phase domain can then be considered and enables to determine solubility limits and phase equilibria [32].

In this work, five diffusion couples were made to investigate the effect of Mo, Ta, $\mathrm{V}$ and $\mathrm{Zr}$ on a reference quaternary alloy $\mathrm{Ti}_{42} \mathrm{Nb}_{42} \mathrm{Al}_{15} \mathrm{Si}_{1}$ [33] with an initial well-known bcc $+\mathrm{O}$ microstructure. The stability of the $\mathrm{O}$ phase was assessed by quantifying the evolution of the orthorhombic phase fraction according to the content of the alloying elements. The design method developed in this study will be detailed in thereafter. Simulated phase diagrams were also calculated and compared to the experimental data in order to assess the predictive ability of available thermodynamic database and to give vector of potential improvement.

\section{Experimental procedures}

Alloys were designed so that only two elements diffuse in the different dif70 fusion couples. Six alloys, $\mathrm{Ti}_{42} \mathrm{Nb}_{42} \mathrm{Al}_{15} \mathrm{Si}_{1}$, whose microstructure and phase 
transition was studied in detail in a previous work [33], $\left(\mathrm{Ti}_{17}, \mathrm{Zr}_{25}\right) \mathrm{Nb}_{42} \mathrm{Al}_{15} \mathrm{Si}_{1}$ and $\mathrm{Ti}_{42}\left(\mathrm{Nb}_{17}, \mathrm{X}_{25}\right) \mathrm{Al}_{15} \mathrm{Si}_{1}$, with $\mathrm{X}=\mathrm{Mo}$, Ta, $\mathrm{V}$ and $\mathrm{Zr}$, were elaborated by vacuum arc-melting using raw elements with high purity $(\geq 99.99$ wt.\%) and under an argon pressure of 250 mbar to obtain ingots of $48 \times 10 \times 17 \mathrm{~mm}^{3}$. 75 These ingots were further cut in samples of $10 \times 10 \times 5 \mathrm{~mm}^{3}$ and then mechanically polished. The polished samples were put in contact with each other in a graphite container (Fig.1). Alumina disks, tungsten foils covered with sprayed BN and niobium foils were placed in the container to prevent contamination. Finally, a tantalum mass of $150 \mathrm{~g}$ was placed to keep the assembly under compression. This set-up was then placed in a furnace at $1300{ }^{\circ} \mathrm{C}$ for $40 \mathrm{~h}$ under 1 atm of static argon atmosphere. This assembling step allows to obtain the diffusion gradient which results in the mechanical link between the two alloys. The diffusion couples were then cut in three slices of $10 \times 10 \times 3 \mathrm{~mm}^{3}$ to check the quality of the assembly and for further precipitation treatment. They were wrapped in tantalum foils and placed in sealed quartz tubes under a vacuum of $10^{-4} \mathrm{~Pa}$ for heat treatment at $800{ }^{\circ} \mathrm{C}$ and $900{ }^{\circ} \mathrm{C}$ for different time periods between 8 and 24 hours, followed by furnace cooling. In the initial $\mathrm{Ti}_{42} \mathrm{Nb}_{42} \mathrm{Al}_{15} \mathrm{Si}_{1}$ alloy, thermodynamic equilibrium was reached after $4 \mathrm{~h}$ for annealing at $800{ }^{\circ} \mathrm{C}$ and $2 \mathrm{~h}$ for annealing at $900{ }^{\circ} \mathrm{C}$ as can be seen in Table. 1 .

\begin{tabular}{llllllll}
\hline \multirow{2}{*}{$\mathrm{T}\left({ }^{\circ} \mathrm{C}\right)$} & \multicolumn{2}{l}{$(\mathrm{h})$} & & & & & \\
\cline { 2 - 8 } & 0.5 & 1 & 2 & 4 & 15 & 48 & 168 \\
\hline 800 & 19 & 32 & 40 & 44 & 44 & 44 & 44 \\
\hline 900 & 23 & 32 & 38 & 38 & 38 & - & - \\
\hline
\end{tabular}

Table 1: Orthorhombic phase fraction (\%) according to annealing temperature and time for the initial $\mathrm{Ti}_{42} \mathrm{Nb}_{42} \mathrm{Al}_{15} \mathrm{Si}_{1}$ alloy [33]

The annealing times in this study were designed so that, they are at least four times the minimum duration to get the maximum $\mathrm{O}$ phase volume fraction in the parent $\mathrm{Ti}_{42} \mathrm{Nb}_{42} \mathrm{Al}_{15} \mathrm{Si}_{1}$ alloy [33], which should ensure thermodynamic equilibrium. The different diffusion couples made and the corresponding heat treatments are summed-up in Table.3. Chemical analysis for $\mathrm{O}, \mathrm{N}$ and $\mathrm{C}$ were done on a (Ti,Zr)NbAlSi and a (Ti,Zr)NbAlSi/TiNbAlSi couple to ascertain the contamination induced by the high temperature treatment. $\mathrm{O}$ and $\mathrm{N}$ were analysed by fusion under inert gas atmosphere and the carbon was analysed by combustion in pure oxygen atmosphere. The results 
are showed in Table.2. Since the assembling procedure is identical for each couple, similar amount of $\mathrm{O}, \mathrm{N}, \mathrm{C}$ can be found in the other couples.

\begin{tabular}{llll}
\hline \multirow{2}{*}{ Sample } & \multicolumn{3}{l}{ Concentration (ppm) } \\
\cline { 2 - 4 } & $\mathrm{O}$ & $\mathrm{C}$ & $\mathrm{N}$ \\
\hline (Ti,Zr)NbAlSi (before assembling) & 410 & 43 & 140 \\
\hline (Ti,Zr)NbAlSi/TiNbAlSi (after assembling) & 850 & 44 & 326 \\
\hline
\end{tabular}

Table 2: $\mathrm{O}, \mathrm{N}$ and $\mathrm{C}$ content before and after assembling

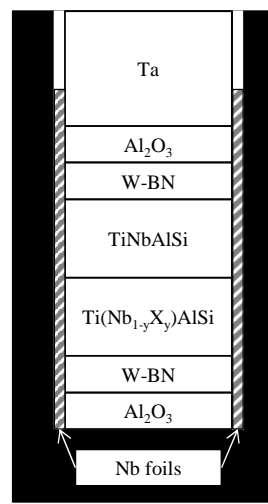

Assembling treatment

Precipitation treatment

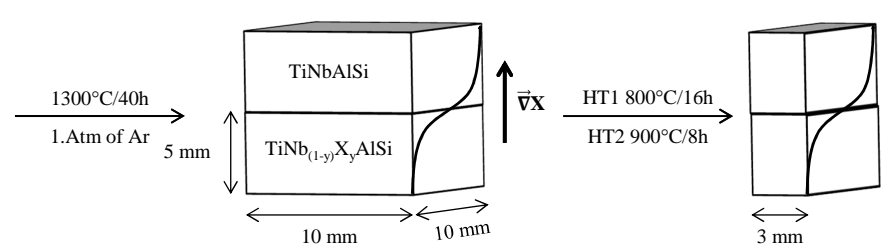

Figure 1: Schematic diagram showing the assembly of the diffusion couples

All couples, except the $\mathrm{Ta} / \mathrm{Nb}$ couple, were analysed by scanning electron microscopy (SEM ZEISS GEMINI) equipped with a back-scattered electron (BSE) and an EDS-SAMXPLUS energy dispersive spectroscopy (EDS) detectors. The concentration profiles after assembling were quantitatively measured in comparison to pure $\mathrm{Nb}, \mathrm{Si}, \mathrm{Mo}, \mathrm{V}, \mathrm{Ta}, \mathrm{Zr}$ standards and stoechiometric $\mathrm{Ti}_{3} \mathrm{Al}$ standard, using IDFIX software. The $\mathrm{Ta} / \mathrm{Nb}$ couple was analysed using a SEM ZEISS MERLIN equiped with EDS-SAMXPLUS EDS and WDS-SAMXPLUS wavelength dispersive spectroscopy (WDS) detectors. The concentration profiles were quantitatively measured by coupling EDSWDS in comparison to the same standards. Nb, Ti and Al were measured by EDS using IDFIX software and Ta, Si were measured by WDS using 
XMASPLUS software. After a precipitation treatment, spectral maps were recorded and each pixel was quantified by EDS in comparison to the same standards using MAXVIEW software. Every quantification was performed using the $\mathrm{K}_{\alpha}$ ray for $\mathrm{Al}, \mathrm{Si}, \mathrm{Ti}$ and $\mathrm{V}$, the $\mathrm{L}_{\alpha}$ ray for $\mathrm{Nb}, \mathrm{Mo}$ and $\mathrm{Zr}$, and the $\mathrm{M}_{\alpha}$ ray for Ta. The phase volume fraction was measured by image analysis using ImageJ software on ten different images for each couple. Thermodynamic simulations were achieved using ThermoCalc software with TCTI1 thermodynamic database. Vickers microhardness measurements (averaged on 100 indents) were performed using a pyramidal diamond tip under $200 \mathrm{~g}$ load applied for $15 \mathrm{~s}$.

\begin{tabular}{ccc}
\hline Couples & \multicolumn{2}{c}{ Heat treatment time $(\mathrm{h})$} \\
\cline { 2 - 3 } & $800^{\circ} \mathrm{C}$ & $900^{\circ} \mathrm{C}$ \\
\hline $\mathrm{Ti}_{42}\left(\mathrm{Nb}_{17}, \mathrm{Mo}_{25}\right) \mathrm{Al}_{15} \mathrm{Si}_{1} / \mathrm{Ti}_{42} \mathrm{Nb}_{42} \mathrm{Al}_{15} \mathrm{Si}_{1}$ & $16 \mathrm{~h}$ & $8 \mathrm{~h}$ \\
\hline $\mathrm{Ti}_{42}\left(\mathrm{Nb}_{17}, \mathrm{Ta}_{25}\right) \mathrm{Al}_{15} \mathrm{Si}_{1} / \mathrm{Ti}_{42} \mathrm{Nb}_{42} \mathrm{Al}_{15} \mathrm{Si}_{1}$ & $24 \mathrm{~h}$ & $16 \mathrm{~h}$ \\
\hline $\mathrm{Ti}_{42}\left(\mathrm{Nb}_{17}, \mathrm{~V}_{25}\right) \mathrm{Al}_{15} \mathrm{Si}_{1} / \mathrm{Ti}_{42} \mathrm{Nb}_{42} \mathrm{Al}_{15} \mathrm{Si}_{1}$ & $16 \mathrm{~h}$ & $16 \mathrm{~h}$ \\
\hline $\mathrm{Ti}_{42}\left(\mathrm{Nb}_{17}, \mathrm{Zr}_{25}\right) \mathrm{Al}_{15} \mathrm{Si}_{1} / \mathrm{Ti}_{42} \mathrm{Nb}_{42} \mathrm{Al}_{15} \mathrm{Si}_{1}$ & $16 \mathrm{~h}$ & $8 \mathrm{~h}$ \\
\hline$\left(\mathrm{Ti}_{17}, \mathrm{Zr}_{25}\right) \mathrm{Nb}_{42} \mathrm{Al}_{15} \mathrm{Si}_{1} / \mathrm{Ti}_{42} \mathrm{Nb}_{42} \mathrm{Al}_{15} \mathrm{Si}_{1}$ & $16 \mathrm{~h}$ & $8 \mathrm{~h}$ \\
\hline
\end{tabular}

Table 3: Summary of the heat treatment temperatures and time periods for each diffusion couple

The approach used to analyse the diffusion couples is described in Fig.2. An area at the interface between the bcc $+\mathrm{O}$ and the bcc domains was chosen in order to observe the precipitation gradient of the $\mathrm{O}$ phase. This area was then cut in slices of equal width of $2 \mu \mathrm{m}$ to $5 \mu \mathrm{m}$, depending on the length of the analysed area. Each slice was then analysed, on one hand, for microstructural characterization using image analysis, by quantifying the $\mathrm{O}$ phase surface fraction of the slice, which was done on ten different areas along the interface. And on the other hand, for chemical analysis using spectral mapping. The pixels in each slice were summed-up and the corresponding total spectrum was quantified to obtain a mean chemical composition of the slice. Then EDS profiles were made along the height of the slice to quantify the chemical scattering. In the end, each slice had a set of data composed of the orthorhombic phase fraction and the chemical composition, and the corresponding scattering. This analysis is made under the assumption that local equilibrium is achieved at the interface between the matrix and precipitates [34]. 


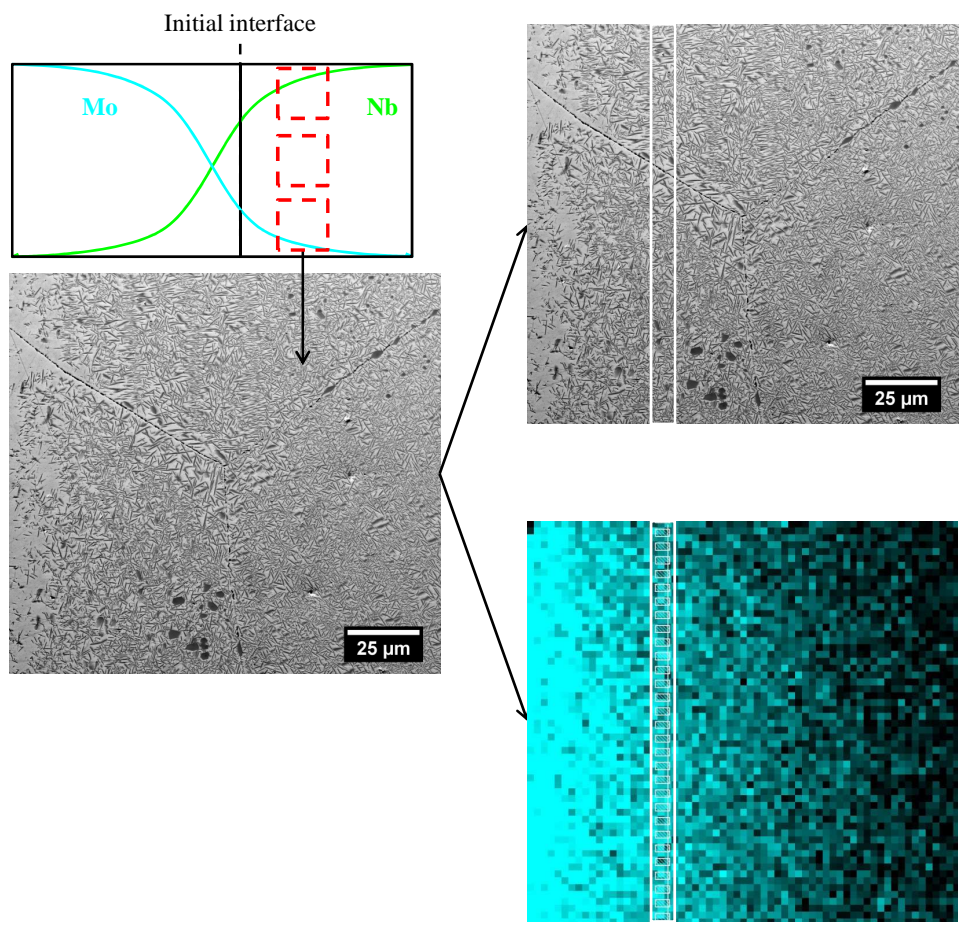

Figure 2: Principle of the method to study diffusion couples after precipitation treatment. Example of the $\mathrm{Mo} / \mathrm{Nb}$ couple after heat treatment at $900^{\circ} \mathrm{C}$. An area at the interface between the bcc $+\mathrm{O}$ and the bcc domains is chosen and the analysed area is cut in slices of equal width. For each slice the $\mathrm{O}$ phase fraction is measured by image analysis. A corresponding $64 \mathrm{x} 64 \mathrm{px}$ quantitative spectral image is acquired and the pixels in each slice are summed-up and quantified in order to obtain a mean chemical composition of the slice. EDS profiles along the height of each slice are done in order to measure the chemical scattering.

\section{Results}

\subsection{After assembling treatment}

Fig.3a shows a SEM-BSE image of the initial interface after assembling of the $\mathrm{Mo} / \mathrm{Nb}$ couple. A good adhesion is observed between the two initial alloys without any particular contamination at the interface. Some silicides (dark grey precipitates) of $(\mathrm{Ti}, \mathrm{Nb}, \mathrm{X})_{5}(\mathrm{Si}, \mathrm{Al})_{3}$ composition $(\mathrm{X}=\mathrm{Mo}, \mathrm{Ta}, \mathrm{V}$ or $\mathrm{Zr})$ are observed. However, their low fraction $(<1.5 \%)$ will not affect the global chemistry of the specimen. 


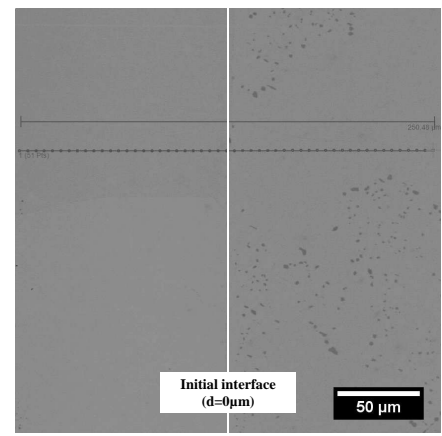

(a)

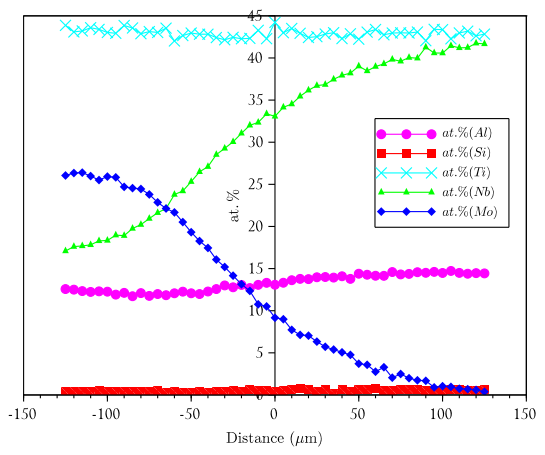

(b)

Figure 3: $\mathrm{Mo} / \mathrm{Nb}$ Couple after assembling at $1300^{\circ} \mathrm{C}$ for $40 \mathrm{~h}$, (a) SEM-BSE showing the EDS dots and (b) the corresponding concentration profiles (at.\%)

EDS profiles were made across the initial interface (Fig.3b) to check the quality of the assembly and to measure the chemical gradient. It extends from 25 at.\%(Mo) to 0 at.\%(Mo) and from 17 at.\%(Nb) to 42 at.\%(Nb) over approximatively $300 \mu \mathrm{m}$. A low $\mathrm{Al}$ gradient can also be observed, and is due to a difference in the nominal composition of the $\mathrm{Ti}(\mathrm{Nb}, \mathrm{Mo}) \mathrm{AlSi}$ end member. However, the deviation remains low if compared to the Mo gradient and will have a slight effect on the following analysis. These measurements confirm that only two elements have diffused during the treatment (here $\mathrm{Nb}$ and $\mathrm{Mo}$ ) while the others remain almost constant. It allows to analyse the effect of one element at a time on the microstructure after precipitation. Gradients for other couples also extend over $300 \mu \mathrm{m}$ to $800 \mu \mathrm{m}$ with, in each case, only two diffusing elements.

\subsection{After precipitation treatment}

SEM-BSE images of the Mo/Nb couple after precipitation treatment at $800^{\circ} \mathrm{C}$ (Fig.4a) and $900^{\circ} \mathrm{C}$ (Fig.4b) are shown. The evolution of the microstructure can be observed on each image from a single bcc phase area on the left (higher Mo content) to a two-phase bcc $+\mathrm{O}$ (black needles) area on the right (lower Mo content). Some silicides were still observed after the precipitation treatments but they will not affect the analysis since their fraction remains low and there is no evolution in their nature nor in their fraction. Fig.4c represents the profiles obtained by applying the method of 

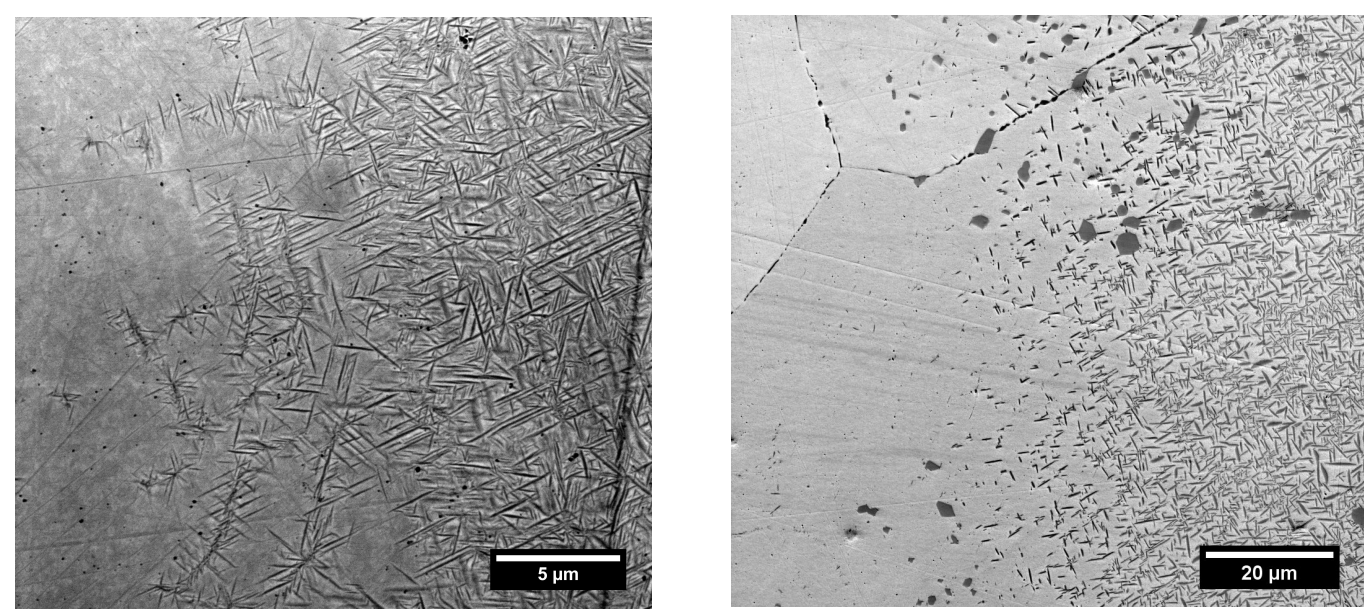

(a)

(b)

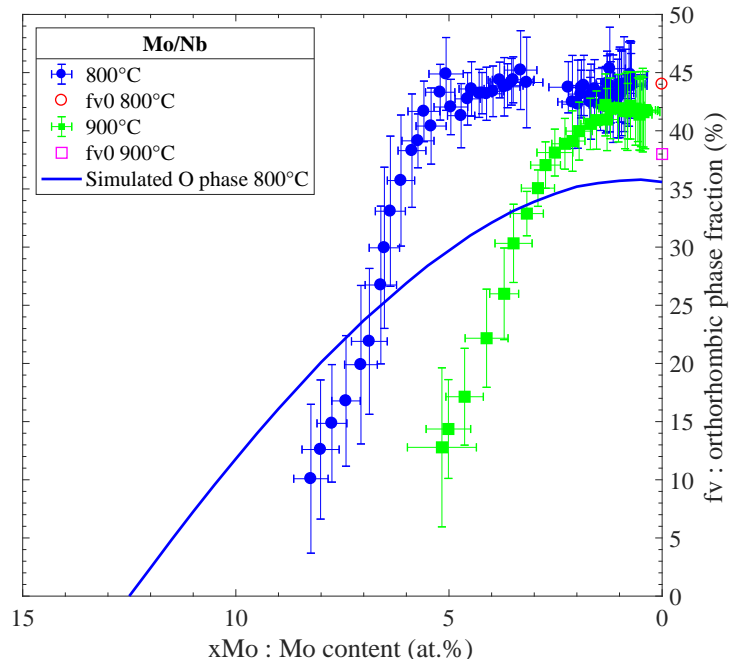

(c)

Figure 4: $\mathrm{Mo} / \mathrm{Nb}$ Couple after assembling at $1300^{\circ} \mathrm{C}$ for $40 \mathrm{~h}$ and precipitation treatments, (a) SEM-BSE after precipitation treatment at $800^{\circ} \mathrm{C}$ for $16 \mathrm{~h}$, (b) SEM-BSE after precipitation treatment at $900^{\circ} \mathrm{C}$ for $8 \mathrm{~h}$ and (c) Experimental and simulated (using TCTI1 database) orthorhombic phase fraction (\%) evolution according to Mo content (at.\%) after precipitation at $800^{\circ} \mathrm{C}$ and $900^{\circ} \mathrm{C}$. The orthorhombic phase fractions denoted fv0 in the initial Ti-Nb-Al-Si are also reported at the corresponding temperature. The different grey levels are an image of the chemical contrast. 


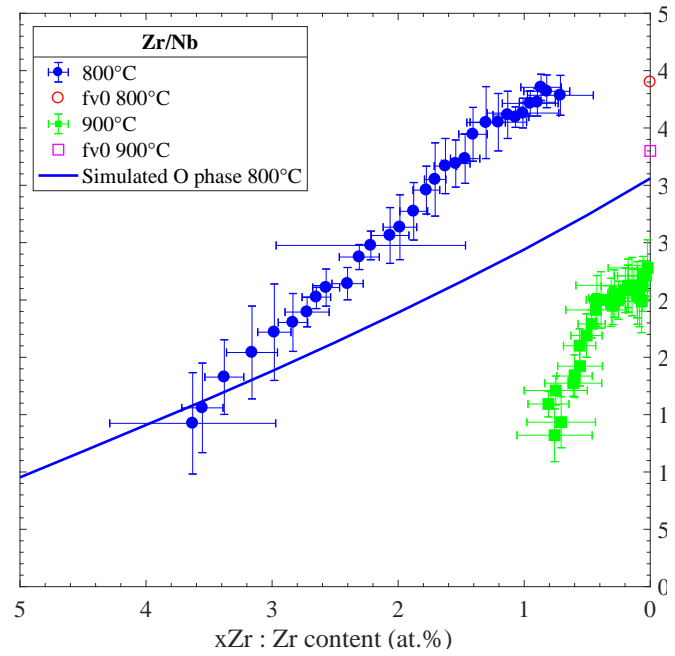

(a)

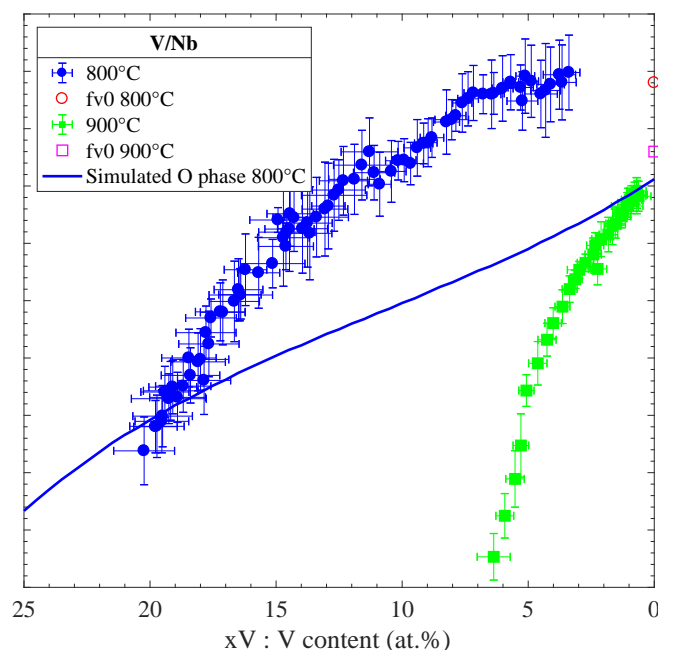

(c)

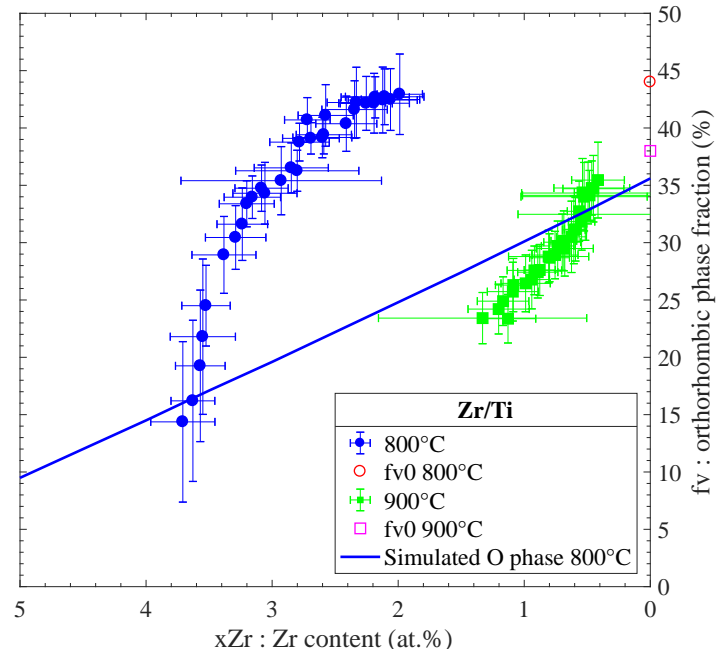

(b)

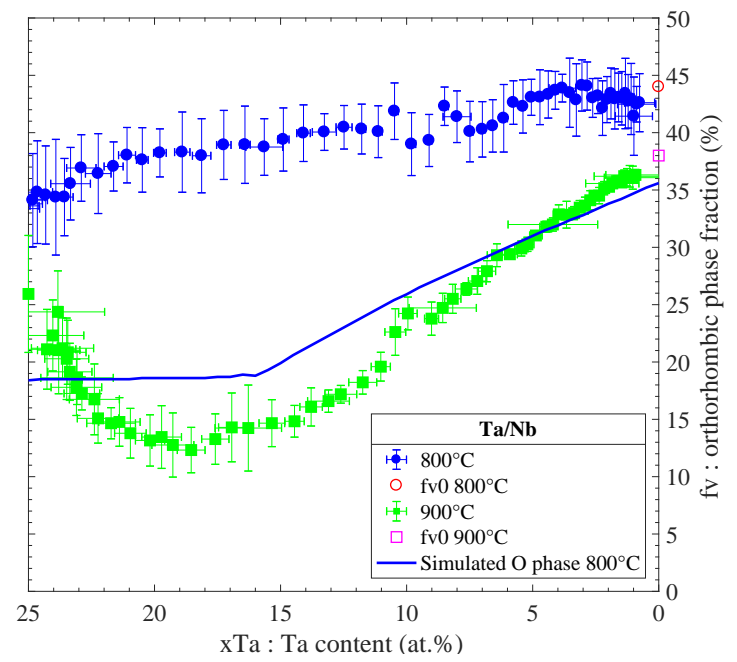

(d)

Figure 5: Experimental and simulated orthorhombic phase fraction (\%) evolution according to element content (at.\%) for, (a) $\mathrm{Zr} / \mathrm{Nb}$, (b) $\mathrm{Zr} / \mathrm{Ti}$, (c) $\mathrm{V} / \mathrm{Nb}$ and (d) $\mathrm{Ta} / \mathrm{Nb}$, couples after precipitation at $800^{\circ} \mathrm{C}$ and $900^{\circ} \mathrm{C}$ 
analysis explained in section. 2 on the $\mathrm{Mo} / \mathrm{Nb}$ couple after precipitation treatment at $800^{\circ} \mathrm{C}$ and $900^{\circ} \mathrm{C}$. The phase volume fraction denoted fv0, measured on the $\mathrm{Ti}_{42} \mathrm{Nb}_{42} \mathrm{Al}_{15} \mathrm{Si}_{1}$ at the corresponding temperatures are also reported (open, red circle and purple square) on the graph [33]. On both curves, the orthorhombic phase fraction remains steady and starts decreasing after a threshold value with increasing Mo content. For $\mathrm{Mo} / \mathrm{Nb}$ couple, at $800^{\circ} \mathrm{C}$ and $900^{\circ} \mathrm{C}$, these values are respectively 5.5 at.\%(Mo) and 3.5 at.\%(Mo). to approximate the end of the bcc $+\mathrm{O}$ domain which is around 9 at.\%(Mo) and 6.5 at. $\%(\mathrm{Mo})$ at $800^{\circ} \mathrm{C}$ and $900^{\circ} \mathrm{C}$, respectively.

The method is then applied to the other couples and the corresponding profiles showing the evolution of the orthorhombic phase fraction for, $\mathrm{Zr} / \mathrm{Nb}$, $\mathrm{Zr} / \mathrm{Ti}, \mathrm{V} / \mathrm{Nb}$ and $\mathrm{Ta} / \mathrm{Nb}$ couples, are displayed in Fig.5. Several trends can be highlighted depending on the considered element. $\mathrm{Zr}$, both in $\mathrm{Zr} / \mathrm{Nb}$ (Fig.5a) and Zr/Ti (Fig.5b) couples, shows a limited two-phase domain with a fast decrease of the $\mathrm{O}$ phase fraction with increasing $\mathrm{Zr}$ content. At $800^{\circ} \mathrm{C}$ the two-phase domain is limited below 5 at.\%(Zr) and 4 at.\%(Zr) for $\mathrm{Zr} / \mathrm{Nb}$ and $\mathrm{Zr} / \mathrm{Ti}$, respectively. A sharp drop of the $\mathrm{O}$ phase fraction with increasing $\mathrm{Zr}$ content is evidenced in the $\mathrm{Zr} / \mathrm{Ti}$ couple. While, at $900^{\circ} \mathrm{C}$ the considered domain is limited below 1 at.\%(Zr) and 3 at.\%(Zr) for $\mathrm{Zr} / \mathrm{Nb}$ and $\mathrm{Zr} / \mathrm{Ti}$ couples respectively. In the $\mathrm{V} / \mathrm{Nb}$ couple (Fig.5c), $\mathrm{V}$ exhibits a vast twophase domain at $800^{\circ} \mathrm{C}$ up to 24 at.\%(V), still with a decrease from $44 \%$ of phase in the vanadium free alloy to less than $12 \%$ above 20 at.\%(V). It also greatly lessen at $900^{\circ} \mathrm{C}$ with the dissolution of the $\mathrm{O}$ phase above 6.5 at. $\%(\mathrm{~V})$ and a phase volume fraction mostly below 35\%. Ta (Fig.5d) displays the most important two-phase domain up to 25 at. $\%(\mathrm{Ta})$, both at $800^{\circ} \mathrm{C}$ and $900^{\circ} \mathrm{C}$. Moreover the $\mathrm{O}$ phase fraction remains high and above $30 \%$ at $800^{\circ} \mathrm{C}$, on all of the concentration range. At $900^{\circ} \mathrm{C}$ it gradually decreases from $38 \%$ of $\mathrm{O}$ phase to $12 \%$ between 0 at. $\%$ (Ta) and 18 at.\%(Ta) and then it steadily increases until it reaches $26 \%$ of $\mathrm{O}$ phase at 25 at.\%(Ta). This surprising trend will be discussed in the next section.

Applied on each diffusion couple, the method allows to determine the maximum additive element values (section.4.3). Moreover, under the assumption that a local equilibrium is achieved [31], it is possible to extrapolate an approximation of the boundary between the single phase bcc domain and the two-phase bcc+O domain. As stated by Kobayashi et al., the assumption is valid if composition gradients are not greater than 10 at.\% per $\mu \mathrm{m}[34]$. In the current study, the formed composition gradient is $\sim 0.3 \mathrm{at} . \%$ 
per $\mu \mathrm{m}$, the effect of the gradient on the local equilibrium between the bcc and the $\mathrm{O}$ phase can therefore be neglected. The corresponding values are listed in Table.4. Zr has a very low maximum additive element content and a limited dual phase domain, both at $800^{\circ} \mathrm{C}$ and $900^{\circ} \mathrm{C}$. Mo has a higher 210 domain compared to $\mathrm{Zr}$. V has a vast two-phase domain up to 24 at.\% at $800^{\circ} \mathrm{C}$ but it significantly decreases at $900^{\circ} \mathrm{C}$. Only the $\mathrm{Ta} / \mathrm{Nb}$ couple shows a vast two-phase domain up to 25 at. $\%(\mathrm{Ta})$, both at $800^{\circ} \mathrm{C}$ and $900^{\circ} \mathrm{C}$.

\subsection{Thermodynamics simulations}

Simulated equilibrium phase diagram for $\mathrm{Ti}_{42} \mathrm{Nb}_{42} \mathrm{Al}_{15} \mathrm{Si}_{1}$ alloy using commercial TCTI1 database was calculated upstream of this work. The orthorhombic phase is described in the TCTI1 database and it is able to calculate phase equilibria between the bcc and $\mathrm{O}$ phases in the Ti-Nb-Al-Si-X system. Nevertheless, and as exposed in Fig.6, some differences are noticeable between experimental data and calculations especially on the dissolution temperature, with an underestimation of about a $60^{\circ} \mathrm{C}$ compared to kinetic experiments, $890^{\circ} \mathrm{C}$ calculated against $946^{\circ} \mathrm{C}$ measured by differential thermal analysis. But also on the orthorhombic phase fraction, with a simulated volume fraction of $35.5 \%$ compared to the $44 \%$ measured at $800^{\circ} \mathrm{C}$ [33]. The presence of $\mathrm{M}_{5} \mathrm{Si}_{3}$-type silicides is also predicted with a constant volume fraction around $2.5 \%$, in good agreement with the observations.

Fig.7a shows the simulated phase diagrams of the $\mathrm{Ti}_{42} \mathrm{Nb}_{42-x} \mathrm{Al}_{15} \mathrm{Si}_{1}-\mathrm{X}_{x}$ and $\mathrm{Ti}_{42-x} \mathrm{Nb}_{42} \mathrm{Al}_{15} \mathrm{Si}_{1}-\mathrm{X}_{x}$ systems, with $\mathrm{X}=\mathrm{Mo}, \mathrm{V}$ and $\mathrm{Zr}$, and Fig.7b with $\mathrm{X}=\mathrm{Ta}$, and the corresponding experimental data points measured on the different diffusion couples (Table.4). Overall, the simulated diagrams quite differ with the experiments on the limits of the two-phase bcc $+\mathrm{O}$ domain both in terms of temperature and compositions. A systematic underestimation at $900^{\circ} \mathrm{C}$ and overestimation at $800^{\circ} \mathrm{C}$ (Fig.7a) is highlighted, except for the simulated $\mathrm{Ta} / \mathrm{Nb}$ couple. At $800^{\circ} \mathrm{C}$, the simulated $\mathrm{Mo} / \mathrm{Nb}$ couple shows a large single phase bcc domain above 12.5 at.\%(Mo) while an extended two-phase domain up to 30 at.\%(V) is observed for the simulated V/Nb couple. Calculations also suggest that Zr has an identical effect whatever the considered couple, with a limited two-phase domain under 7 at.\%(Zr). The simulated $\mathrm{Ta} / \mathrm{Nb}$ couple (Fig.7b) also shows an extended two-phase domain up to 30 at.\%(Ta). Moreover two chemically different orthorhombic phases $\mathrm{O} \# 1$ and $\mathrm{O} \# 2$ are predicted with a coexistence domain between 16 at.\%(Ta) and 17 at.\%(Ta). 


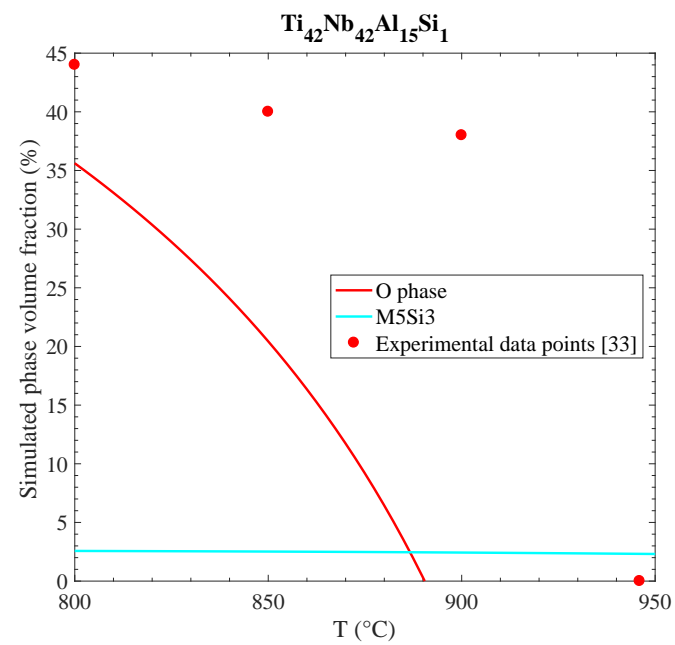

Figure 6: Simulated equilibrium phase diagram using the TCTI1 database for $\mathrm{Ti}_{42} \mathrm{Nb}_{42} \mathrm{Al}_{15} \mathrm{Si}_{1}$

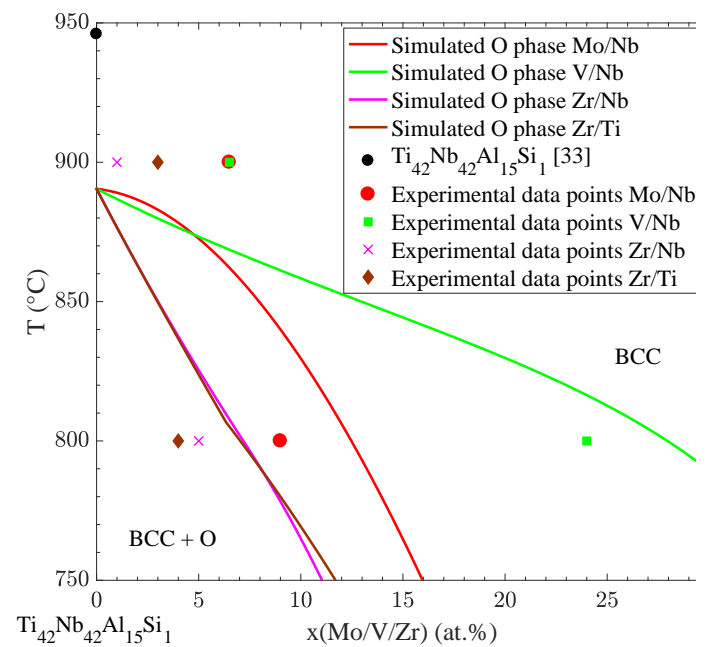

(a)

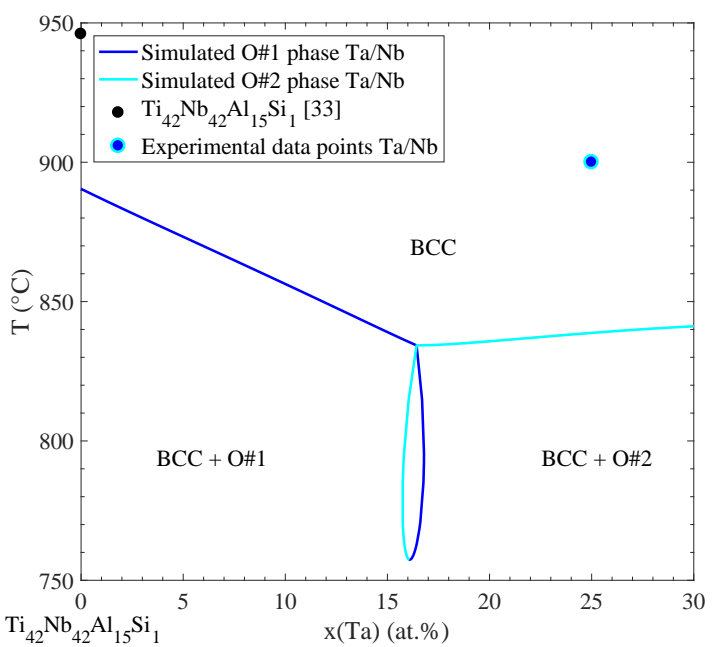

(b)

Figure 7: Simulated phase diagrams, using TCTI1 database, for (a) Mo/Nb, V/Nb, Zr/Nb and $\mathrm{Zr} / \mathrm{Ti}$ and (b) Ta/Nb couples. The solid lines illustrate the simulated $\mathrm{O}$ phase solvus for each couple and the dots show the experimental data points extrapolated at $800^{\circ} \mathrm{C}$ and $900^{\circ} \mathrm{C}$ 
Fig.4c and Fig.5 shows the evolution of the simulated phase volume fraction according to the concentration of the alloying element (at.\%) for each of the considered elements in the $\mathrm{TiNb}_{42-x} \mathrm{X}_{x} \mathrm{AlSi}$ and $\mathrm{Ti}_{42-x} \mathrm{X}_{x} \mathrm{NbAlSi}$ systems. Mo (Fig.4c) and Zr (Fig.5a and Fig.5b) both lead to a continuous decrease in the $\mathrm{O}$ phase volume fraction on their respective intervals. At $800^{\circ} \mathrm{C}$, increasing Mo content from 0 at.\%(Mo) to 12.5 at.\%(Mo) decreases the $\mathrm{O}$ phase volume fraction from $35.5 \%$ until it disappears at 12.5 at.\%(Mo) while increasing $\mathrm{Zr}$ content from 0 at.\%(Zr) to 5 at.\%(Zr), decreases in each case the $\mathrm{O}$ phase volume fraction from $35.5 \%$ to $9.5 \%$. Only V (Fig.5c) and Ta (Fig.5d) show a two-phase bcc+O domain until 30 at.\% but increasing $\mathrm{V}$ content produce a steady decrease in the $\mathrm{O}$ phase volume fraction from $35.5 \%$ to $7 \%$ whereas Ta addition first causes a decrease from $35.5 \%$ to $18 \%$ in the O phase volume fraction at 16 at.\%(Ta) after which it remains constant.

\begin{tabular}{cccc}
\hline Couple & Temperature $\left({ }^{\circ} \mathrm{C}\right)$ & $\begin{array}{c}\text { Maximum additive } \\
\text { element content } \\
\text { (at.\%) }\end{array}$ & End of domain (at.\%) \\
\hline $\mathrm{Mo} / \mathrm{Nb}$ & 800 & 5.5 & 9 \\
\hline $\mathrm{Ta} / \mathrm{Nb}$ & 900 & 3.5 & 2.5 \\
\hline $\mathrm{V} / \mathrm{Nb}$ & 800 & 14 & $\geq 25$ \\
\hline $\mathrm{Zr} / \mathrm{Nb}$ & 900 & 5.5 & 24 \\
\hline \multirow{2}{*}{$\mathrm{Zr} / \mathrm{Ti}$} & 900 & 8 & 6.5 \\
\hline
\end{tabular}

Table 4: Summary of, the maximum additional element content (at.\%), that enables to keep $40 \%$ and $30 \%$ of the $\mathrm{O}$ phase fraction at $800^{\circ} \mathrm{C}$ and $900^{\circ} \mathrm{C}$ respectively, and the extrapolated end of dual phase domain (at.\%) for each couple after precipitation at $800^{\circ} \mathrm{C}$ and $900^{\circ} \mathrm{C}$

\section{Discussion}

\subsection{Effect of temperature on the experimental and simulated phase evolution} and phase stability

Overall, whatever the additional element, a heat treatment at $900^{\circ} \mathrm{C}$ is closer to the dissolution temperature of the $\mathrm{O}$ phase than a heat treatment at $800^{\circ} \mathrm{C}$, so it has more limited two-phase field and $\mathrm{O}$ phase volume fraction 
(Fig.5). This can be understood by looking at the ternary Ti-Nb-Al phase diagrams [35]. The $\mathrm{O}$ phase is stable on a very narrow domain of composition up to $1000^{\circ} \mathrm{C}$. The TCTI1 database well reproduces this trend but systematically underestimates the $\mathrm{O}$ phase domain at $900^{\circ} \mathrm{C}$ and overestimates it at $800^{\circ} \mathrm{C}$.

These differences are related to the incorrect description of the $\mathrm{O}$ phase domain in the database. In particular, it results from a lack of accuracy on the $\mathrm{O}$ phase dissolution temperature in the initial $\mathrm{Ti}_{42} \mathrm{Nb}_{42} \mathrm{Al}_{15} \mathrm{Si}_{1}$ system. The stabilizing effect of $\mathrm{Si}$ on the $\mathrm{O}$ phase [33] is not taken into account, which is then impacted on the whole diagram. Furthermore, except for Ta, the different alloying elements have zero solubility in the simulated $\mathrm{O}$ phase. Since there are no solute elements in the O phase, no defaults are introduced hence a lesser disorder in this phase. As a consequence, the entropy of the $\mathrm{O}$ phase may be underestimated. For a given temperature, an underestimation of the entropy of the $\mathrm{O}$ phase leads to a higher free energy. At higher temperature such as $900^{\circ} \mathrm{C}$ the underestimation of the $\mathrm{O}$ phase entropic term is more important, therefore the systematic underestimation of its domain. The entropic term is also underestimated at $800^{\circ} \mathrm{C}$, but the enthalpy also decreases with the temperature, thus two opposite effects are involved. However the enthalpy variation according to temperature is greater than the entropy variation, which may lead to the overestimated $\mathrm{O}$ phase domain at $800^{\circ} \mathrm{C}$.

\subsection{Effect of composition on the experimental and simulated phase evolution and phase stability}

To discuss the effect of chemical composition, it may be interesting to first regroup all the studied elements as in the Ti alloys with Mo, Ta and V labelled as $\beta$-stabilizers and $\mathrm{Zr}$ as a neutral element [36]. Then, based on the curves in Fig.5, it also seems relevant to discuss the effect of Ta apart from the other $\beta$-stabilizers. Overall at $800^{\circ} \mathrm{C}$, except for the $\mathrm{Ta} / \mathrm{Nb}$ couple, the simulated domains are overestimated in terms of additive element concentration and the $\mathrm{O}$ phase volume fraction is underestimated. Here again, the simulations show good trendlines and qualitative evolution but lack in accuracy. All these differences are probably due to a lack of thermodynamic data on binary and ternary systems to accuratly predict quaternary or higher equilibrium for this system, as already mentionned in the literature [5]. 


\subsubsection{Effect of $\beta$-stabilizers $M o$ and $V$}

Therefore, concerning the limits of the bcc+O two-phase domain for Mo and V (Fig.4c and Fig.5c respectively), EDS measurements were possible on $\mathrm{V} / \mathrm{Nb}$ couples after a heat treatment at $800^{\circ} \mathrm{C}$ and the phase compositions are summed-up in Table.5. These measurements were not possible on the $\mathrm{Mo} / \mathrm{Nb}$ couple since the $\mathrm{O}$ precipitates size is too small to allow SEM-EDS analysis.

\begin{tabular}{ccccccc}
\hline Couple & Phase & $\mathrm{Ti}$ & $\mathrm{Nb}$ & $\mathrm{Al}$ & $\mathrm{Si}$ & $\mathrm{V}$ \\
\hline \multirow{2}{*}{$\mathrm{V} / \mathrm{Nb}$} & $\beta$-phase & $39.5 \pm 0.5$ & $20.9 \pm 0.4$ & $13.8 \pm 0.3$ & $0.8 \pm 0.2$ & $25.0 \pm 0.5$ \\
& Orthorhombic & $55.6 \pm 2.6$ & $13.0 \pm 1.4$ & $20.4 \pm 0.9$ & $1.5 \pm 0.2$ & $9.5 \pm 2.3$ \\
\hline
\end{tabular}

Table 5: Phase composition (at.\%) of $\mathrm{V} / \mathrm{Nb}$ couple after heat treatment at $800^{\circ} \mathrm{C}$ at $\mathrm{x}_{V}^{\text {Global }}=23$ at.\%. The measurements were performed at an acceleration voltage of $7 \mathrm{kV}$.

The partition coefficient of the element, $\mathrm{X}: P_{X}=x_{X}^{O} / x_{X}^{\beta}$ has been determined from these measurements, which for $\mathrm{V}$ is quite large $P_{V}=0.38 \pm 0.09$. Both high partition coefficient and large two-phase domain could lead, at equivalent element content, to a greater stability of the $\mathrm{O}$ phase and thus to an extended two-phase domain. Accordingly, based on the measurements on the $\mathrm{V} / \mathrm{Nb}$ couple, it can be assumed that there is also a partial solubility of Mo in the orthorhombic phase and that $P_{M o}$ should be smaller than $P_{V}$. Thus, it can be assumed that, in the case of the $\beta$-stabilizer element, i.e Mo and V, the higher the partition coefficient is, the greater the two-phase domain is. Overall, these two elements displayed their $\beta$-stabilizing role by favoring the bcc phase over the $\mathrm{O}$ phase with increasing concentration. With Mo and $\mathrm{V}$ being isomorphous with the $\beta$-phase, thus extending its domain of stability at lower temperature and leading to a stable bcc solid solution. Moreover, from the analysis of simulations results, it was noticed that the selected alloying elements had no solubility in the $\mathrm{O}$ phase in the database. As a consequence, the additional elements will enrich the bcc phase which will induce necessary adjustments relative to, the composition and volume fraction of $\mathrm{O}$ phase to keep the quantity of matter balanced, and to minimize the Gibbs free energy of the system. Hence the inaccuracy noticed in the phase diagrams and in the evolution of the $\mathrm{O}$ phase volume fraction. 


\subsubsection{Effect of $Z r$}

As observed, Zr appears as the less favorable additive element for the stability of the $\mathrm{O}$ phase, both in the simulations and experiments, and contrary

to the common belief in Ti alloys, it acts as a strong $\beta$-stabilizer. Past studies suggest that $\mathrm{Zr}$ can modify the solubility of an element in a phase and so change its stability. It is the case in Ti-Zr-Si alloys [37], for which $\mathrm{Zr}$ addition reduces the solubility of $\mathrm{Si}$ in the $\beta$-Ti phase, thus leading to the early precipitation of silicides. Similarly in the $\mathrm{Zr} / \mathrm{Nb}$ and $\mathrm{Zr} / \mathrm{Ti}$ couples, $\mathrm{Zr}$ addition might change the solubility of an element ( $\mathrm{Al}$ for example), increasing its solubility in the $\beta$ phase. Consequently the $\beta$ phase would remain highly stable, hence the fast disappearance of the $\mathrm{O}$ phase and the existence of a single bcc phase domain with increasing $\mathrm{Zr}$ concentration. Until it reaches higher $\mathrm{Zr}$ concentration where it leads to the precipitation of a zirconium aluminide phase. CALPHAD calculations show a competition between the precipitation of an $\mathrm{Al}_{3} \mathrm{Zr}_{5}$ phase and the $\mathrm{O}$ phase, which could be responsible of the limited existence of the latter. Again, there is no simulated solubility of $\mathrm{Zr}$ in the $\mathrm{O}$ phase, so a $\mathrm{Zr}$ enriched bcc phase with enough $\mathrm{Al}$ quickly leads to the precipitation of a zirconium aluminide since Al-Zr intermetallics are highly stable phases [38]. However, even if a zirconium aluminide phase was indeed observed experimentally, it was at higher $\mathrm{Zr}$ content. And no coexistence betweenn an $\mathrm{Al}_{3} \mathrm{Zr}_{5}$ and an $\mathrm{O}$ phases was observed.

\subsubsection{Effect of $\mathrm{Ta}$}

The intermetallic orthorhombic phase has two different structures according to the temperature: the $\mathrm{O} 1$ phase is the high temperature structure and the $\mathrm{O} 2$ phase is the low temperature one [39, 40], as illustrated in Fig.8. Both have the same space group and only differ in the site occupancy [39, 40]. Moreover, an orthorhombic $\mathrm{Ti}_{2} \mathrm{AlTa}\left(\mathrm{Ti}_{2.17} \mathrm{Al}_{1.06} \mathrm{Ta}_{0.77}\right)$ was reported [41], which should also display the two different structures O1 and O2, depending on the temperature. Accordingly, it can be assumed that the Ti-Al-Ta system presents a similar phase diagram as the Ti-Al-Nb system, but where the stability domains would be shifted in temperature.

Knowing this, three scenario can be considered, that may explain the evolution of the $\mathrm{O}$ phase fraction observed at $900^{\circ} \mathrm{C}$ and $800^{\circ} \mathrm{C}$. At $900^{\circ} \mathrm{C}$, two extrema at 0 at.\% (Ta) and 25 at.\% (Ta) and a minimum in between at 16 at.\% (Ta) were observed (Fig.5d), which can be explained firstly by a competition between two chemically different phases, $\mathrm{O}_{-} \mathrm{Ti}_{2} \mathrm{Al}(\mathrm{Nb}, \mathrm{Ta})$ and $\mathrm{O}-$ $\mathrm{Ti}_{2} \mathrm{Al}(\mathrm{Ta}, \mathrm{Nb})$. Two dual phase domains, $\mathrm{BCC}+\mathrm{O}-\mathrm{Ti}_{2} \mathrm{Al}(\mathrm{Nb}, \mathrm{Ta})$ and $\mathrm{BCC}+\mathrm{O}-$ 


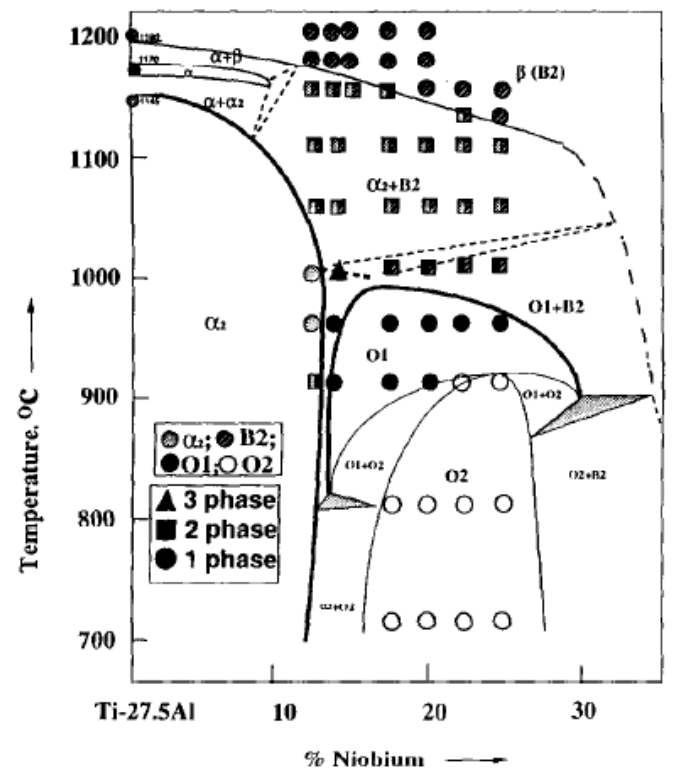

Figure 8: Schematic phase diagram of the Ti-Al-Nb system showing the O1 and O2 phases [39]

$\mathrm{Ti}_{2} \mathrm{Al}(\mathrm{Ta}, \mathrm{Nb})$ would exist at 0 at. $\%(\mathrm{Ta})$ and 25 at.\%(Ta) respectively, hence the extrema. While at 16 at.\%(Ta), there is the coexistence of the two phases $\mathrm{O}-\mathrm{Ti}_{2} \mathrm{Al}(\mathrm{Nb}, \mathrm{Ta})$ and $\mathrm{O}-\mathrm{Ti}_{2} \mathrm{Al}(\mathrm{Ta}, \mathrm{Nb})$, and actually a three-phase domain $\mathrm{BCC}+\mathrm{O}-\mathrm{Ti}_{2} \mathrm{Al}(\mathrm{Nb}, \mathrm{Ta})+\mathrm{O}-\mathrm{Ti}_{2} \mathrm{Al}(\mathrm{Ta}, \mathrm{Nb})$, resulting in a competition of precipitation between these phases and thus leading to a slower precipitation kinetic. However this scenario seems unlikely since, if a competition were occuring between $\mathrm{O}-\mathrm{Ti}_{2} \mathrm{Al}(\mathrm{Nb}, \mathrm{Ta})$ and $\mathrm{O}-\mathrm{Ti}_{2} \mathrm{Al}(\mathrm{Ta}, \mathrm{Nb})$ for their precipitation, it should take place at every temperature. Which is not the case at $800^{\circ} \mathrm{C}$ (Fig.5d). This implies that only the difference in chemistry can not explain the behaviour displayed at $900^{\circ} \mathrm{C}$. If the structure of the $\mathrm{O}$ phase, i.e $\mathrm{O} 1$ and $\mathrm{O} 2$, is taken into account, then depending on the temperature, there are two possible cases. Either $\mathrm{O}-\mathrm{Ti}_{2} \mathrm{Al}(\mathrm{Nb}, \mathrm{Ta})$ and $\mathrm{O}-\mathrm{Ti}_{2} \mathrm{Al}(\mathrm{Ta}, \mathrm{Nb})$ have different structures or they both share the same. In the first case, the coexistence of an $\mathrm{O} 1$ phase and an $\mathrm{O} 2$ phase means there are actually two distinct phases with different cristallography. Whereas in the second case, independently of the chemical composition, there is only one orthorhombic phase with either 
the $\mathrm{O} 1$ or $\mathrm{O} 2$ structure. The coexistence of the two structures could then lead to a competition of their precipitation, resulting in a slower precipitation kinetic. While on the contrary, the existence of only one $\mathrm{O}$ phase with either $\mathrm{O} 1$ or $\mathrm{O} 2$ structure could allow a continuous substitution of an element by an other on the $\mathrm{Nb} / \mathrm{Ta}$ site. Following this, at $900^{\circ} \mathrm{C}$, there would be two phases $\mathrm{O}-\mathrm{Ti}_{2} \mathrm{Al}(\mathrm{Nb}, \mathrm{Ta})$ and $\mathrm{O}-\mathrm{Ti}_{2} \mathrm{Al}(\mathrm{Ta}, \mathrm{Nb})$ but with different structure, one being $\mathrm{O} 1$ and the other $\mathrm{O} 2$. Then at 0 at.\%(Ta) and 25 at.\%(Ta), there would be two dual phase domains, one $\mathrm{BCC}+\mathrm{O} 1$ and the other $\mathrm{BCC}+\mathrm{O} 2$, hence the two extrema. While at 16 at.\%(Ta), there is the coexistence of the two phases $\mathrm{O} 1$ and $\mathrm{O} 2$, and actually a three-phase domain $\mathrm{BCC}+\mathrm{O} 1+\mathrm{O} 2$, hence the minimum of $\mathrm{O}$ phase fraction, due to a competition between $\mathrm{O} 1$ and $\mathrm{O} 2$, resulting in a slower precipitation kinetic. Subsequently, at $800^{\circ} \mathrm{C}$ both phases would have the same structure and then there is actually only one orthorhombic phase, $\mathrm{O}-\mathrm{Ti}_{2} \mathrm{Al}(\mathrm{Nb}, \mathrm{Ta})$ with either the $\mathrm{O} 1$ or $\mathrm{O} 2$ structure, along the chemical gradient with a continuous substitution of $\mathrm{Nb}$ by Ta. Hence the slight and continuous decrease of the $\mathrm{O}$ phase fraction along the gradient. This two cases are illustrated in the schematic phase diagram (Fig.9). The fact that the $\mathrm{O}$ phase fraction decreases with increasing Ta content may be an evidence that the $\mathrm{O}-\mathrm{Ti}_{2} \mathrm{Al}(\mathrm{Nb}, \mathrm{Ta})$ phase is more stable than the $\mathrm{O}-\mathrm{Ti}_{2} \mathrm{Al}(\mathrm{Ta}, \mathrm{Nb})$ phase [42]. If this hypothesis is verified, it would also means that one of the $\mathrm{O}$ phase, $\mathrm{O}-\mathrm{Ti}_{2} \mathrm{Al}(\mathrm{Nb}, \mathrm{Ta})$ or $\mathrm{O}-\mathrm{Ti}_{2} \mathrm{Al}(\mathrm{Ta}, \mathrm{Nb})$, has a transition from the $\mathrm{O} 1$ structure to the $\mathrm{O} 2$ structure at a temperature between $800^{\circ} \mathrm{C}$ and $900^{\circ} \mathrm{C}$. This hypothesis deserves further analysis.

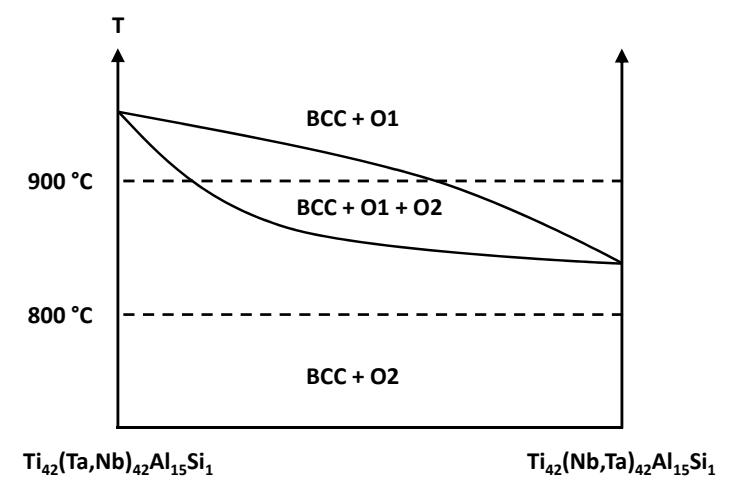

Figure 9: Schematic $\mathrm{Ti}_{2} \mathrm{AlTa} / \mathrm{Ti}_{2} \mathrm{AlNb}$ phase diagram showing the $\mathrm{O} 1$ and $\mathrm{O} 2$ phases and their respective domains 
The simulated phase diagram (Fig.7b) well-predicts the extended O phase domain and suggests the possible coexistence of two chemically different orthorhombic phases, but on a very narrow domain of composition. However the simulations do not take ordering effect into account, so do not discriminate the $\mathrm{O} 1$ and the $\mathrm{O} 2$ structures but rather predict two $\mathrm{O}$ phases with distinct chemical compositions but identical structure. As explained, this seems rather unlikely at $800^{\circ} \mathrm{C}$ since the coexistence of two $\mathrm{O}$ phases should ead to a competition for the precipitation of these phases. In any case, the fact that an orthorhombic phase in the Ti-Al-Ta system was reported is most likely the reason why the $\mathrm{Ta} / \mathrm{Nb}$ couple was the most well described by the CALPHAD simulations. However, the simulated O phase fraction is highly underestimated in comparison to the experimental data at $800^{\circ} \mathrm{C}$.

\subsection{Alloy design}

The control the microstructure is crucial to plan potential structural application. The nature, the morphology and the distribution of the strengthening phase, are key parameters to consider. Based on previous research on the Ti-Nb-Al system made by Boehlert [15], selection criteria on the orthorhombic phase fraction can be chosen. In order to achieve high resistance at elevated temperatures with an acceptable room temperature ductility, a required $40 \%$ of $\mathrm{O}$ phase is needed at $800^{\circ} \mathrm{C}$ and $30 \%$ at $900^{\circ} \mathrm{C}$. With these criteria, in the case of the $\mathrm{Mo} / \mathrm{Nb}$ couple, it is possible to evaluate the maximum additive element content of 5.5 at.\%(Mo) and 3.5 at.\%(Mo) respectively, to the quaternary system. Based on these criteria it is also possible to note (see Table.4) that $\mathrm{Zr}$ is quite unfavorable to the stability of the $\mathrm{O}$ phase and any addition of this element will likely be disadvantageous to this alloy system. Whereas Mo, V and Ta are more interesting additive elements, with higher solubility in the quaternary system. Addition of one of these elements will likely have a greater impact on the properties of this alloy system and will give room to potential benefits compared to the quaternary alloy. To clarify the reliability of this method, an alloy with the $\mathrm{Ti}_{42}\left(\mathrm{Nb}_{37}, \mathrm{Mo}_{5}\right) \mathrm{Al}_{15} \mathrm{Si}_{1}$ composition was prepared and heat-treated at $1300^{\circ} \mathrm{C} / 40 \mathrm{~h}$ followed by annealing at $800^{\circ} \mathrm{C} / 16 \mathrm{~h}(\mathrm{Fig} .10)$. The measured volume fraction of the $\mathrm{O}$ phase is $f_{v}=42 \% \pm 4 \%$ which is in agreement with the measurements made on the Mo/Nb couple. Moreover, Vickers hardness measurements show an improved RT microhardness of $462 H_{v} \pm 21 H_{v}$ compared to $392 H_{v} \pm 9 H_{v}$ for the $\mathrm{Ti}_{42} \mathrm{Nb}_{42} \mathrm{Al}_{15} \mathrm{Si}_{1}$ alloy [33]. 


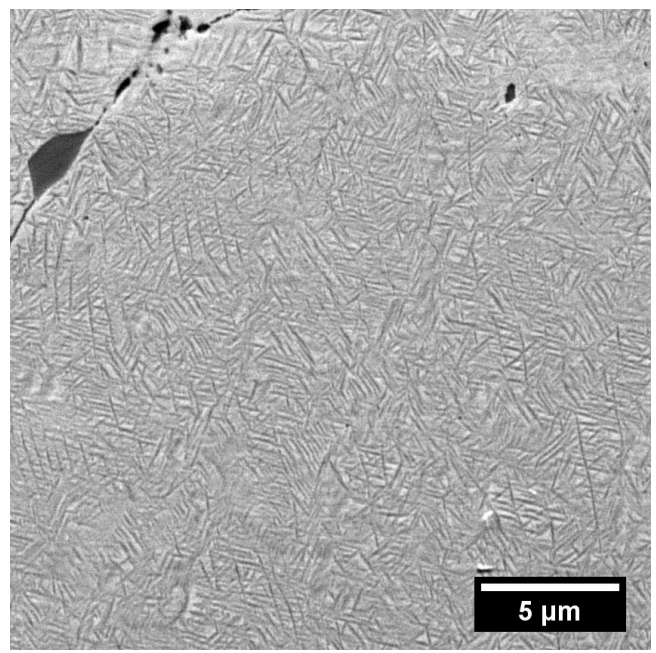

Figure 10: SEM-BSE image of a $\mathrm{Ti}_{42} \mathrm{Nb}_{37} \mathrm{Mo}_{5} \mathrm{Al}_{15} \mathrm{Si}_{1}$ after heat treatment at $1300^{\circ} \mathrm{C}$ followed by annealing at $800^{\circ} \mathrm{C}$ showing a bcc $+\mathrm{O}$ microstructure

In an approach aimed at developing alloys for structural application, it is now possible, with this diffusion couples based method, to target alloy compositions that can ensure an already optimized microstructure for the targeted application. However, and in spite of the speed-up of the screening process, alloys designed with this procedure should still be characterized afterwards, since more in-depth analysis is quite difficult to implement on the graded samples.

\section{Summary and conclusions}

Five diffusion couples were prepared, allowing to experimentally assess the effect of $\mathrm{Mo}, \mathrm{Ta}, \mathrm{V}$ and $\mathrm{Zr}$ on the microstructure evolution of an initial bcc $+\mathrm{O} \mathrm{Ti}_{42} \mathrm{Nb}_{42} \mathrm{Al}_{15} \mathrm{Si}_{1}$ alloy at $800^{\circ} \mathrm{C}$ and $900^{\circ} \mathrm{C}$. A SEM analysis strategy was implemented and enabled to quantify the evolution of the orthorhombic phase fraction according to the concentration of the alloying element. This method allowed to determine a maximum additive element content and to extrapolate the limits of the bcc+O domain. It showed that $\mathrm{Mo}, \mathrm{V}$ and $\mathrm{Zr}$ all destabilized the $\mathrm{O}$ phase whereas Ta showed a continuous two-phase bcc $+\mathrm{O}$ domain along the chemical gradient. Thermodynamic simulations, using the commercial TCTI1 database, were made and a systematic comparison to experimental data were performed. Although, on refractory alloys, it 
gives qualitative trends with a good agreement between predicted phases and observed ones, it fails to accuratly predict the phase transition and the phase volume fraction. As a consequence, the TCTI1 database is not reliable enough to be used as a predictive tool for alloy design. According to these results, a fast, reliable and experimental alloy design method was presented. By using selective criteria on the $\mathrm{O}$ phase fraction it was possible to determine a maximum additive concentration for each alloying element. This method allows to target alloy compositions that can ensure an already optimized microstructure. It highlighted that addition of Mo, Ta and V are more interesting additive element for a potential improved duplex bcc $+\mathrm{O}$ alloys whereas $\mathrm{Zr}$ is more incline to be unfavourable.

\section{Acknowledgements}

465 The authors would like to thank Cédric Lopes, Patrick Pradines, Etienne Rimpot, Sébastien Mercier, Valérie Lalanne and Loic Perrière for their help in the experiment and their involvement on each stage of the study. The authors also would like to thanks Jean-Marc Joubert for is kind suggestions and help on the revision process. This work was performed in the ANR

framework programme TURBO-AHEAD.

\section{References}

\section{References}

[1] B. Cantor, I.T.H. Chang, P. Knight, and A.J.B. Vincent. Microstructural development in equiatomic multicomponent alloys. Materials Science and Engineering: A, 375:213-218, 2004.

[2] J.W. Yeh, S.J. Lin, T.S. Chin, J.Y. Gan, S.K. Chen, T.T. Shun, C.H. Tsau, and S.Y. Chou. Formation of simple crystal structures in Cu-CoNi-Cr-Al-Fe-Ti-V alloys with multiprincipal metallic elements. Metallurgical and Materials Transactions A, 35(8):2533-2536, 2004.

480

[3] O.N. Senkov, G.B. Wilks, D.B. Miracle, C.P. Chuang, and P.K. Liaw. Refractory high-entropy alloys. Intermetallics, 18(9):1758-1765, 2010.

[4] D.B. Miracle and O.N. Senkov. A critical review of high entropy alloys and related concepts. Acta Materialia, 122:448-511, 2017. 
[5] O.N. Senkov, D.B. Miracle, K.J. Chaput, and J.P. Couzinie. Development and exploration of refractory high entropy alloys - a review. Journal of Materials Research, pages 1-37, 2018.

[6] O.N. Senkov, S.V. Senkova, and C. Woodward. Effect of aluminum on the microstructure and properties of two refractory high-entropy alloys. Acta Materialia, 68:214-228, 2014.

[7] B. Schuh, B. Völker, J. Todt, N. Schell, L. Perrière, J. Li, J.P. Couzinié, and A. Hohenwarter. Thermodynamic instability of a nanocrystalline, single-phase TiZrNbHfTa alloy and its impact on the mechanical properties. Acta Materialia, 142:201-212, 2018.

[8] N.D. Stepanov, N.Y. Yurchenko, D.V. Skibin, M.A. Tikhonovsky, and G.A. Salishchev. Structure and mechanical properties of the AlCrxNbTiV ( $\mathrm{x}=0,0.5,1,1.5)$ high entropy alloys. Journal of Alloys and Compounds, 652:266-280, 2015.

[9] V. Soni, O.N. Senkov, B. Gwalani, D.B. Miracle, and R. Banerjee. Microstructural design for improving ductility of an initially brittle refractory high entropy alloy. Scientific reports, 8(1):8816, 2018.

[10] S. Naka and T. Khan. Alloy design. In Intermetallic CompoundsPrinciples and Practice: Progress, editors, John Wiley E Sons, Ltd, volume 3, pages 841-855. Wiley Online Library, New-York, 2002.

[11] A.K. Gogia, T.K. Nandy, D. Banerjee, T. Carisey, J.L. Strudel, and J.M. Franchet. Microstructure and mechanical properties of orthorhombic alloys in the Ti-Al-Nb system. Intermetallics, 6(7-8):741-748, 1998.

[12] C.J. Boehlert, B.S. Majumdar, V. Seetharaman, and D.B. Miracle. Part i. the microstructural evolution in Ti-Al-Nb O + BCC orthorhombic alloys. Metallurgical and Materials Transactions A, 30(9):2305-2323, 1999.

[13] D. Banerjee, A.K. Gogia, T.K. Nandi, and V.A. Joshi. A new ordered orthorhombic phase in a Ti3Al-Nb alloy. Acta Metallurgica, 36(4):871 882, 1988. 
[14] C.J. Cowen and C.J. Boehlert. Microstructure, creep, and tensile behavior of a Ti-21Al-29Nb (at.\%) orthorhombic+ B2 alloy. Intermetallics, 14(4):412-422, 2006.

[15] C.J. Boehlert. Part iii. the tensile behavior of Ti-Al-Nb O + BCC orthorhombic alloys. Metallurgical and Materials Transactions A, 32(8):1977-1988, 2001.

[16] A.K. Gogia, T.K. Nandy, K. Muraleedharan, and D. Banerjee. The effect of heat treatment and niobium content on the room temperature tensile properties and microstructure of Ti3Al-Nb alloys. Materials Science and Engineering: A, 159(1):73-86, 1992.

[17] L. Germann, D. Banerjee, J.Y. Guédou, and J.L. Strudel. Effect of composition on the mechanical properties of newly developed Ti2AlNbbased titanium aluminide. Intermetallics, 13(9):920 - 924, 2005. 2nd IRC International TiAl Workshop.

[18] F. Tang, S. Nakazawa, and M. Hagiwara. The effect of quaternary additions on the microstructures and mechanical properties of orthorhombic Ti2AlNb-based alloys. Materials Science and Engineering: A, 329331:492 - 498, 2002.

[19] Y. Mao, S. Li, J. Zhang, J. Peng, D. Zou, and Z. Zhong. Microstructure and tensile properties of orthorhombic $\mathrm{Ti}-\mathrm{Al}-\mathrm{Nb}-\mathrm{Ta}$ alloys. Intermetallics, 8(5):659 - 662, 2000.

[20] T.B. Zhang, G. Huang, R. Hu, and J.S. Li. Microstructural stability of long term aging treated $\mathrm{Ti}-22 \mathrm{Al}-26 \mathrm{Nb}-1 \mathrm{Zr}$ orthorhombic titanium aluminide. Transactions of Nonferrous Metals Society of China, 25(8):2549 $-2555,2015$.

[21] M.C. Gao. Computational thermodynamic and kinetic modeling of highentropy alloys and amorphous alloys. JOM, 64(7):828-829, Jul 2012.

[22] M.C. Gao, C.S. Carney, Ö.N. Doğan, P.D. Jablonksi, J.A. Hawk, and D.E. Alman. Design of refractory high-entropy alloys. JOM, 67(11):2653-2669, Nov 2015. 
[23] O.N. Senkov, J.D. Miller, D.B. Miracle, and C. Woodward. Accelerated exploration of multi-principal element alloys for structural applications. Calphad, 50:32 - 48, 2015.

[24] K.N. Wertz, J.D. Miller, and O.N. Senkov. Toward multi-principal component alloy discovery: Assessment of CALPHAD thermodynamic databases for prediction of novel ternary alloy systems. Journal of $\mathrm{Ma}$ terials Research, 33(19):3204-3217, 2018.

[25] G. Bracq, M. Laurent-Brocq, L. Perrière, R. Pirès, J.M. Joubert, and I. Guillot. The fcc solid solution stability in the Co-Cr-Fe-Mn-Ni multicomponent system. Acta Materialia, 128:327 - 336, 2017.

[26] O.N Senkov, S.V. Senkova, C. Woodward, and D.B. Miracle. Lowdensity, refractory multi-principal element alloys of the $\mathrm{Cr}-\mathrm{Nb}-\mathrm{Ti}-$ V-Zr system: Microstructure and phase analysis. Acta Materialia, 61(5):1545-1557, 2013.

[27] D. Kuroda, M. Niinomi, M. Morinaga, Y. Kato, and T. Yashiro. Design and mechanical properties of new $\beta$ type titanium alloys for implant materials. Materials Science and Engineering: A, 243(1-2):244-249, 1998.

[28] L. Lilensten, J.P. Couzinié, J. Bourgon, L. Perrière, G. Dirras, F. Prima, and I. Guillot. Design and tensile properties of a bcc Ti-rich high-entropy alloy with transformation-induced plasticity. Materials Research Letters, $5(2): 110-116,2017$.

[29] J.C. Zhao. A combinatorial approach for structural materials. Advanced engineering materials, 3(3):143-147, 2001.

[30] J.C. Zhao. A combinatorial approach for efficient mapping of phase diagrams and properties. Journal of Materials Research, 16(6):1565$1578,2001$.

[31] J.C. Zhao. Reliability of the diffusion-multiple approach for phase diagram mapping. Journal of materials science, 39(12):3913-3925, 2004.

[32] T. Miyazaki, T. Koyama, and S. Kobayashi. A new characterization method of the microstructure using the macroscopic composition gradient in alloys. Metallurgical and Materials Transactions A, 27(4):945-949, 1996. 
[33] L. Sikorav. Evaluation du système $\mathrm{Nb}$-Ti-Al+Si: Influence de la composition chimique et du dopage au silicium sur les transformations de phases. PhD thesis, Université Pierre et Marie Curie, 2017.

[34] S. Kobayashi, Y. Tsukamoto, T. Takasugi, H. Chinen, T. Omori,

580

585

590 K. Ishida, and S. Zaefferer. Determination of phase equilibria in the Co-rich $\mathrm{Co}-\mathrm{Al}-\mathrm{W}$ ternary system with a diffusion-couple technique. Intermetallics, 17(12):1085-1089, 2009.

[35] V.T. Witusiewicz, A.A. Bondar, U. Hecht, and T.Ya. Velikanova. The $\mathrm{Al}-\mathrm{B}-\mathrm{Nb}-\mathrm{Ti}$ system: Iv. experimental study and thermodynamic reevaluation of the binary $\mathrm{Al}-\mathrm{Nb}$ and ternary $\mathrm{Al}-\mathrm{Nb}-\mathrm{Ti}$ systems. Journal of Alloys and Compounds, 472(1):133 - 161, 2009.

[36] M.J. Donachie. Titanium: a technical guide. ASM international, 2000.

[37] N.H. Salpadoru and H.M. Flower. Phase equilibria and transformations in a Ti-Zr-Si system. Metallurgical and Materials Transactions A, 26(2):243-257, Feb 1995.

[38] R. Tamim and K. Mahdouk. Thermodynamic reassessment of the Al-Zr binary system. Journal of Thermal Analysis and Calorimetry, 131(2):1187-1200, Feb 2018.

[39] K. Muraleedharan, T.K. Nandy, D. Banerjee, and S. Lele. Phase stability and ordering behaviour of the $\mathrm{O}$ phase in $\mathrm{Ti}-\mathrm{Al}-\mathrm{Nb}$ alloys. Intermetallics, 3(3):187-199, 1995.

[40] K. Muraleedharan, T.K. Nandy, D. Banerjee, and S. Lele. Transformations in a Ti-24Al-15Nb alloy: Part ii. a composition invariant $\beta_{0} \rightarrow \mathrm{O}$ transformation. Metallurgical Transactions A, 23(2):417-431, 1992.

[41] V.T. Witusiewicz, A.A. Bondar, U. Hecht, V.M. Voblikov, O.S. Fomichov, V.M. Petyukh, and S. Rex. Experimental study and thermodynamic modelling of the ternary $\mathrm{Al}-\mathrm{Ta}-\mathrm{Ti}$ system. Intermetallics, 19(3):234 - 259, 2011.

[42] Q.M. Hu, R. Yang, D.S. Xu, Y.L. Hao, D. Li, and W.T. Wu. Geometric and electronic structure of Ti2AlX (X=V, Nb, or Ta). Phys. Rev. B, 68:054102, Aug 2003. 